\title{
La contribución de los lingüistas españoles al COLOQUIO "LATIN VULGAIRE — LATIN TARDIF III" Innsbruck, 2-5 IX 1991, Actas editadas por Maria Iliescu y Werner Marxgut, Niemeyer, Tübingen 1992
}

1. El llamado "latín vulgar", tardío y medieval sigue siendo uno de los temas centrales de la lingüística tanto latina como románica y una prueba son los coloquios internacionales dedicados a este dominio científico: el primer coloquio organizado en Pécs en 1985, el segundo en Bologna en 1988 y el tercero en Innsbruck en 1991 (el cuarto es previsto en Caen, en 1994). En estas páginas queremos presentar y comentar las contribuciones de los lingüistas españoles, especialistas de filología latina, que han participado al último coloquio. La contribución española es algo modesta, ya que de las treinta comunicaciones presentadas solamente cuatro son de filólogos españoles (frente a catorce en alemán y doce en francés). Sin embargo, las ponencias españolas son de evidente interés tanto latino como románico.

\section{Las comunicaciones en castellano son éstas:}

1) Carmen Arias Abellán (Universidad de Sevilla), Sobre el sufijo latino - osus y su empleo con significado "aproximativo" en parte del románico, págs. 11-24;

2) Carmen Gallardo (Universidad de Madrid), Resultado a del diptongo au, pp. 133-141;

3) Olegario García de la Fuente (Universidad de Málaga), Sobre la colocación de los adverbios de cantidad en el latín vulgar y en el latín biblico, págs. 143-157;

4) Benjamin García Hernández (Universidad de Madrid), Nuevos verbos impersonales en latin tardio e influencia griega, págs. 159-172.

Los niveles de descripción lingüística son por lo tanto la fonética, la formación de palabras y la sintaxis. Son los dominios tratados también en la mayoría de las otras ponencias (junto a algunos temas hoy centrales, como la lingüística del texto, la sociolingüística y la pragmática).

3. Carmen Arias Abellán estudia las formaciones con el sufijo -osus especialmente en las expresiones para el color. La alternativa principal es entre el significado aproximativo ya latino o solamente tardío, románico (11). Para la "reducción cromática" el latín se sirve de diminutivos (albulus) y de compuestos (subalbus); cuanto a los primeros, en latín pueden ser sólo denotativos o también afectivos (13). Para expresar la aproximación se encuentran también los participios de presente [nosotros preferimos denominar estas formas participios de simultaneidad, porque son posibles tanto en el presente como en el pasado y el futuro]. Se cita el ejemplo rubens (al cual sería posible añadir formaciones como crocizans "de color semejante a azafrán; crocino" en Oribasio, o subamarizans "un poco amargo" en Dioscóride, que no pertenece al dominio de los colores pero sí tiene el significado aproximativo, atenuado). El latín carecía de expresiones para la aproximación 
cromática (15) y no se le puede atribuir a -osus un valor diminutivo (17). Por otra parte, nace en latín la función del sufijo para expresar la semejanza (aurosus, cinerosus, herbosus, vinosus etc.). La conclusión es que la noción primaria de abundancia de -osus se pierde poco a poco y que este sufijo funciona en la comparación de colores apenas desde los siglos IV y V y, sobre todo, que en latín no hay significado aproximativo, el cual es pues románico, no latino.

4. Una explicación histórica innovadora e interesante nos la proporciona la breve comunicación de Carmen Gallardo. La reducción del diptongo /au/ a /a/ ha sido explicada de diversos modos: a) como un simple error gráfico; b) como disimilación ante una $/ \mathrm{u} / \mathrm{u} / \mathrm{o} /$ [explicación más frecuente y casi general]; c) como resultado de la convergencia de los dos miembros del diptongo (esto es, resultado de la monoptongación progresiva de /au/). En las páginas 135-138 la autora cita una larga serie de ejemplos de disimilación, y también de otros contextos fonéticos (por ejemplo Cladius, Fastina, axilium etc.) y, de lo que parece ser la confusión de $/ \mathfrak{w}$ / (segundo miembro del diptongo) con una consonante (p. ej. attem para autem, abscultare, cabsa etc.).[En el segundo grupo figura también Glacus para Glaucus, que no se distingue en nada de clasula (si vale clausula), voz que se cita en el primer grupo.] La evidente conclusión es que la reducción /au $>$ a/ no está necesariamente ligada a una $/ \mathrm{u} / \mathrm{u} / \mathrm{o} /$ en la sílaba siguiente. Según la hipótesis de la autora los hablantes conservadores queriendo proteger la pronunciación correcta, exageraban cerrando la /u/ en sonido fricativo que ocasionalmente podía convertirse en una oclusiva (139). [Esta consonantización del segundo miembro de /au/ recuerda los llamados diptongos "endurecidos" (verhärtete Diphtonge) de algunos dialectos retorrománicos de Suiza, p. ej. nekf< neif NIVE "nieve".] Habría pues dos pronunciaciones cultas e imitadas por las capas sociales inferiores: 1) /au/ pronunciado como [åo], luego [o] (pronunciación más inculta); 2) /au/ pronunciado como [av/ab], con la posibilidad, también en la lengua de los incultos, de asimilación total de $v / b$ a la consonante siguiente. La presencia de una $/ \mathrm{u} / \mathrm{u} / \mathrm{o} /$ en la sílaba siguiente podía entonces favorecer por su parte la dicha reducción, como factor secundario.

5. Para estudiar la colocación de adverbios de cantidad en el latín vulgar y en el latín bíblico Olegario García de la Fuente escoge la Peregrinatio Aegeriae [sic; de corregir en Egeriae o Aetheriae] para el primero y la Vulgata para el segundo. Pasa en reseña los adverbios nimis, valde, vehementer, satis, amplius, magis, plus, minus, modice/modicum, penitus, plurimum, nimium en ambos textos; multo/multum, fortiter, abundanter, recte, parum y paululum solamente en la Vulgata; ingens e infinitum sólo en la Peregrinatio Egeriae. La comunicación termina con conclusiones sobre la distribución/colocación de los adverbios examinados. Hay que hacer algunas observaciones: 1) $\mathrm{Si}$ - como es usual en la lingüística románica contemporánea - por "latín vulgar" se entiende el conjunto de todas las variedades de latín, lengua viva y hablada, el latín bíblico no puede oponerse al "latín vulgar" sans plus, ya que éste abarca a aquél; 2) Las formas en -ísimo o el positivo precedido de muy (analogamente en los otros idiomas románicos), citadas en la nota 17 (146), no son superlativos sino elativos (estando hoy el superlativo expresado por la perífrasis analítica $e l+$ más/menos + positivo); y, sobre todo, no son superlativos las formas compuestas multo maius, multo minus etc. $(153)$; 3) Es interesante, que en la Peregrinatio el 
adverbio modice/modicum va detrás del verbo en sólo dos casos, ambos con el verbo sedere (152): sedete vobis et modico; sedent modice. ¿Habría una relación particular entre el verbo sedere y la posposición de modice/modicum?

6. Benjamin García Hernández se dedica a los verbos impersonales (los sin sujeto: pluit) y unipersonales (los usados solamente en la $3^{a}$ persona: decet) en latín vulgar, tardío y medieval. Los tres factores de la evolución estudiada son la influencia griega, el cristianismo y el latín vulgar (159), y todos ellos deben tenerse en cuenta. El griego influye sobre el latín con el cristianismo y también por medio de tratados técnicos (Antimo, Dioscóride, Oribasio, Mulomedicina [añádase el tratado conocido como Compositiones Lucenses]). Al lado de la influencia griega hay asimismo factores latinos internos. El autor examina los impersonales intransitivos (capit, est, subiacet, vacat) y los transitivos (cogit, debet, facit, habet). En ciertas ocasiones adquiere importancia una indicación locativa: $\mathrm{p}$. ej. la intransitivación de habet (pérdida del sujeto) parece ligada a la presencia de una determinación espacial: habet bibliotheca librum > habet in bibliotheca librum (167). En latín tardío se difunden los impersonales transitivos y, contemporáneamente, los transitivos tienden a hacerse intransitivos. Estos dos procesos "revelan, en definitiva, la decadencia funcional de la voz pasiva" (168). En la parte final de la comunicación se lee una interesante comparación de tres posibilidades de expresar la noción de habet impersonal [el llamado verbo existencial], esto es esse, habere y dare: c'è, there is/hay, il y a/es gibt (169170). En conclusión:"los nuevos verbos impersonales que surgen en latín tardío bajo el impulso de la lengua griega se desarrollan en un marco evolutivo propio de la lengua latina y gracias a ello consiguen prosperar" (170).

7. Éstas son pues las cuatro contribuciones de los lingüistas de lengua castellana; sin embargo, de temas españoles o por lo menos de formas españolas se trata también en otros textos: véanse p. ej. las páginas del artículo de Y. Malkiel sobre el sufijo -ium en los idiomas románicos (225-232), la etimología del español llegar, portugués chegar, discutida en la comunicación de W. Mańczak (233-241, esp. 236-237), los resultados españoles HOMINEM > hombre, ${ }^{*}$ RETUNDUS > redondo, ERIS > eres, en la contribución de R. de Dardel (83-91, esp. 83-84) etc.

En resumen, las contribuciones españolas así como todas las Actas del III Coloquio sobre el latín vulgar y tardío, merecen ser leídas por cada lingüista interesado en la base latina de las lenguas románicas. Esperamos con comprensible interés las Actas del IV Coloquio. 